\title{
Writing within simultaneity: A reflective progress report through letters from the Wits Writing Programme
}

\section{Pamela Nichols ${ }^{1}$ iD}

Wits Writing Centre and the Centre for Learning, Teaching, and Development, University of the Witwatersrand, South Africa

E-mail: pamela.nichols@wits.ac.za

\section{Zimitri Erasmus}

Department of Anthropology, University of the Witwatersrand, South Africa

E-mail: zimitri.erasmus@wits.ac.za

\section{Nomonde Ntsepo}

Department of English, Rhodes University, Grahamstown, South Africa

E-mail: nomonde.ntsepo@gmail.com

Lerato Mlahleki

Department of Sociology, University of the Witwatersrand, South Africa

E-mail: leratomla@gmail.com

\section{Keanu Mabalane}

Department of Philosophy, University of the Witwatersrand, South Africa E-mail: keanukkmab@gmail.com

\section{Khensani Ngobeni}

Department of Politics, University of the Witwatersrand, South Africa

E-mail: kngobeni1@outlook.com

\section{Lew Is Ckool}

Department of Publishing Studies, University of the Witwatersrand, South Africa E-mail: lewisckool@gmail.com

\section{Abstract}

Listening has long been understood as characteristic of writing centre practice, and as central to writing centre philosophy. This reflective progress report argues that such listening is also the

\footnotetext{
${ }^{1}$ Corresponding author.
} 
generating culture of a university-wide writing programme of writing intensive courses, and that this culture will only be manifested and sustained if constantly modelled at all levels of the programme. In order to model what we teach, we need to build listening into the processes and structure of the programme as well as into the classrooms. Through letters from the invited coauthors of this paper, a snapshot is provided of the generative power of active listening in the teaching conversations between professor and writing fellows; lecturer, writing fellow and students; and writing fellows as a team as they create their lesson plan. Active listening is understood as a discipline of attentiveness to multiple and simultaneous meanings, and thus as a discipline which is necessary for complex thought and writing. Edward Said (2013) has described this attentiveness to simultaneity as key to a humanist critical literacy, which not only promotes engaged students and teachers but is also a political commitment to developing the citizen scholar. In the Wits Writing Programme, attentiveness to simultaneity represents a principle of teaching and of learning, an aim of writing, and a guiding value of the programme's construction.

Keywords: Writing Intensive, critical humanist literacy, citizen scholar

\section{Introduction}

The Wits Writing Programme (WWP) was many years in the making. The idea of a Writing Intensive (WI) programme across the university was introduced in 2001 to a senior Teaching and Learning committee but the argument was not heard ${ }^{2}$. Ideas about writing support were so culturally embedded that the WI programme was assumed to be its opposite - assumed to be writing outside of the discipline - and a bid for institutional turf. Perhaps there was also the confusion of one person with the idea. As I (Pamela Nichols) was associated with the writing centre, and thus walk-in writing consultations plus workshops on demand, a programme of WI courses was not understood as a systemic mainstream project. The documents circulated were clear, but the unwritten cultural assumptions proved to be stronger. Seventeen years later, using some of the same text, and powered by a three-year government grant, the WWP has taken off.

For the last 17 years, seeds were sown through successful WI courses run across the university by allied colleagues not connected to each other, as well as through courses run by colleagues who independently came to similar thinking about embedding writing-to-learn- and learningto-write activities within discipline-specific courses. Professor Elisabeth Brenner and I visited at least 12 universities across South Africa to run day-long, sometimes three-day long, workshops for staff interested in making their courses WI. Our own teaching demonstrated WI techniques, and so gave more people - including future lecturers - the experience of the writing process employed to further complex thought. However, a crucial nudge to the door to open a systemic change in teaching and promote a WI programme was external to the usual ebb and flow of institutional life. The Fees Must Fall (FMF) movement was a fierce social disruption which demanded that all students be more engaged with the intellectual work of the university.

The collective FMF demand was to move from the marginalised periphery to participation in discussions at the centre. Translated into writing terms, this means to move from novice writing (which is characteristically writer-centred, discovers meaning as it goes along, and is without nested or nuanced or positioned argument) to expert writing (which enters and engages a

\footnotetext{
${ }^{2}$ See Brenner and Nichols (2013).
} 
community of scholars and is thus experienced, reader-centred, and finds its argument within a dynamic simultaneity of possible meanings $)^{3}$. It is perhaps no accident that the Department of Anthropology at Wits, which was particularly active during the FMF protests, collectively decided after the protests in 2015 that the adoption of WI methods in all of its courses ${ }^{4}$ would be central to its curriculum transformation.

The need to promote more expert reading and writing is global. In one of his last interviews, Edward Said, interviewed by John Higgins at the University of Cape Town (UCT), warned of the danger of losing critical literacy:

And it is just that level of literacy and attention and hearing that $I$ fear is disappearing. First of all because it's difficult and it requires attention to the simultaneity of voices rather than just one single voice. And this, of course, is what the media has become: just one voice. The media has removed all the overtones, the parallel lines, the implications and consequences and associations of good writing - and good music - have and enjoy.

(Said 2013: 219; current authors' emphasis)

Said's formulation of simultaneity involves far more than multiplicity. It means the comprehension of simultaneous parallel meaning and association, it means working with ambiguity, contingency, and nuance. In short, it denotes complex thinking, a skill which is currently being eroded by social media and group thought. Said believes that the Humanities have a significant role to play in promoting an antidote to superficial reading and writing. As Higgins (2013) argues, the learning of how to read and write while being attentive to a simultaneity of voices and possible meanings is a critical humanist literacy. This needs to be taught and modelled at all levels of teaching so that it can become a way of living ${ }^{5}$.

\section{Practice}

The operational processes ${ }^{6}$ of the WWP formalise ways to give students ongoing attention and develop their own attentiveness, while at the same time ensuring that the programme as a whole encourages listening, self-reflection, and collective growth. WI courses are existing courses which are adapted to use writing to deliver course content, where this latter concept is understood as the particular critical thinking skills which the course is designed to teach. Some courses might already be WI, but all lecturers who want their course recognised as such must first complete a workshop which explains the principles and criteria, and allows lecturers to share strategies to make their course WI. The lecturer then submits a course proposal to the Writing Board of the Faculties (WBF), which comprises representatives of all five faculties.

\footnotetext{
${ }^{3}$ See Colomb and Williams (1990) for further explanation of "novice-" and "expert" writing.

4 This was communicated to Nichols by the then head of department, Dr Kelly Gillespie, who subsequently requested workshops in 2016 for all of the lecturers and postgraduate tutors in Anthropology. The aim of these workshops was to adapt all existing courses to make them WI.

5 This idea of a critical humanist literacy, as developed in the work of scholars like Edward Said and Jakes Gerwel, is applied to South African higher education and the Humanities throughout Higgins' (2013) collection of essays and interviews on academic freedom and democracy.

${ }^{6}$ The continually updated WWP handbook is available on request. For initial institutional development, see Nichols (2017b).
} 
If the course is recognised by the WBF as WI, the WI lecturer is allocated funding for Writing Fellow tutors (WFs).

The WFs are necessary to allow for more interactive and responsive teaching required by WI courses by bringing the student-to-staff ratio down to $25: 1$. (This ratio is slightly higher than the ratio used in many of the programmes in the United States, and is currently being reconsidered by the WBF in order to balance the need to promote active learning with the challenge of large classes and limited funding.) The WI lecturer can source his/her own WFs or can select one or more from the pool of postgraduate tutors from different disciplines who have previously worked as WFs. WFs are also required to attend an initial preparation workshop, which includes a pack of sample activities to support the reading and writing process, before joining their WI lecturer in working as a team to deliver their course. Part of the paid WF work is to meet each week with their WI lecturer to discuss the week's learning, and to think of ways to build on it the following week. Nearly all of the WI lecturers and WFs wrote that this weekly discussion was particularly useful.

As can be seen from the above sketch, opportunities for discussion are created by and necessary for the success of the programme. These include discussions between lecturers designing their courses, among the WBF members as the submissions are considered, between WFs from different disciplines during their training, and then between the $\mathrm{WF}(\mathrm{s})$ and the WI lecturer as the course unfolds. All of these conversations are set up before the delivery of the actual classes, and the last conversation continues throughout the course as the ongoing focal point for reflection and development. These continuing conversations reflect and fuel the learning experience within the classes, which are designed to present learning as something the students will discover and make their own through iterative oral and written conversations with texts, with their peers, with their WFs, and with their lecturer.

The common premises of the WWP are also vital in terms of holding the programme together through a common approach. These include:

- Writing is thinking (thus writing includes reading, discussion, argument construction and evaluation, and is not limited to a particular language or even medium);

- Writing can be used to enhance cognitive processes of learning (therefore across disciplines we can share strategies for promoting sharper and more engaged thinking and its communication);

- Writing can be used to enhance rhetorical awareness and skills (and so develop a better understanding of how meaning is made within disciplines, and thus how to develop excellent writing within disciplines); and

- Attentive listening and response can become the open-ended generative force of WI courses and the WWP as a whole (therefore students discover and construct knowledge rather than simply being given it, with the result that the WWP as a whole evolves through collective engaged thinking) ${ }^{7}$.

\footnotetext{
${ }^{7}$ The first three premises are, of course, common to WI theory and most WI programmes (see, for example, Bean (1996) and the University of Missouri Campus Writing Programme website). The fourth premise has been developed at the Wits Writing Centre, and takes its origins from the American Civil Rights movement and the pedagogy of the Freedom Schools in the South [see Nichols (2016)].
} 
This last premise - that attentive listening and response fuel learning in the classroom, and is the generating force of the programme as a whole - is the subject of this paper because it is what makes every programme unique, and is key to its success or failure. Following Delpit (1995), we work with the assumption that without listening there is no learning, nor change, nor renewal, and listening must be modelled as well as explicitly taught so that it becomes a way of being ${ }^{8}$. Such a commitment to active listening requires a programme to maintain a balance between listening to simultaneous and different positions while finding ways to work together so as to maintain the programme's conceptual distinctiveness. It means heightening and sharpening the conversations, so that we really listen and respond, to carefully find our current position and understanding.

Listening to all, up to a point, is of course a democratic fallacy ${ }^{9}$. Yet as a process we know that it is possible because we have experienced it in a dynamic classroom in which a fierce debate is held and explored for as long as possible, which is open to the new and unexpected, but in the end has to choose its frame and temporarily conclude. It is also the task of this paper to present concurrent voices in the invited letters written by colleagues in the programme and coauthors of this paper, and to respect their differences, yet to frame them together as part of a coherent argument. The task of listening to others is also central to developing the programme as a whole, which now includes creative applications in different disciplines, and multiple visions of how to deliver a successful WI course while finding ways to make sure that we work together with common theory and principles. The task is to listen and hold the vision - always out of complete reach - of the university as a place of academic freedom ${ }^{10}$.

\section{The conversations}

In 2018, there were 29 recognised WI courses running in each of the five faculties, 146 WFs employed, and over 5000 students enrolled. In 2019, there are 40 recognised WI courses with participation from all faculties, $240 \mathrm{WFs}$ employed, and over 8000 students enrolled. As the programme grows, we need to develop different ways to reflect and evaluate. In 2018, all WI lecturers had to submit reports, and all WFs were required to answer 18 evaluative and reflective questions. But lecturers and WFs also asked for the opportunity for less structured thinking together about the programme. Consequently, writing retreats were arranged which included space and time for staff to discuss their courses, and an indaba was requested early in the year to allow for further cross-disciplinary conversation. The letters requested for this paper show this constant thinking about the course, in response to and in conversation with others, sometimes across disciplines, and tied to further everyone's learning.

The following letters profile some of these voices within the programme that share the WWP's dual aim to promote independent critical thought and rhetorical effectiveness within disciplines. They present a selected sample of some of the variety of voices in the programme so as to suggest how the combined voices create a whole. They were selected because they represent different

\footnotetext{
8 See Delpit (1995: 21-22, 46-47).

9 See Carter (2009).

${ }^{10}$ I have written about listening before: the need to listen to individual students in the writing centre (Nichols 2014); listening as the pedagogical principle of the "resonant classroom" in a programme for school children (Nichols 2016); and as a theorised "transitional space" necessary for transformation (Nichols 2017a). This paper extends the investigation of listening into the operations and principles of a university-wide programme, arguing that formal structures and professional interactions need to model this generating practice and principle as much as it needs to be implemented in the classroom.
} 
levels of teaching, and also because student, lecturer, and WF evaluations ${ }^{11}$ indicate that all of these teachers succeeded in achieving high levels of engagement in their classes. These letters provide snapshots into the working and thinking behind and before the classroom, with each letter-writer directing their thoughts from their particular position to another particular position, so as to move us forward. All model the aims of our teaching in the classroom in the way they prepare and think through how to teach. The first letter is from a professor writing to her WFs, letters two and three are from a WI lecturer and her WFs writing to their students, respectively, and the last is from a team of WFs writing to their students.

\subsection{Letter 1: Professor to WFs}

Professor Zimitri Erasmus is an award-winning teacher, and a leading scholar of race ${ }^{12}$. She writes of her own movement from the margin to the centre, and offers a hand of solidarity towards her WFs and her students. That hand of solidarity pulls them towards a questioning stance concerning sociological theory, and indicates a life-long method of working to understand positions behind writing, including one's own. The work which Erasmus models and teaches is not the imparting of knowledge but rather the hard work of understanding. In Said's (2013: 217218 ) words, this hard work is "accessible to any citizen", "certainly pleasurable", and it "brings you back into activity rather than [allowing] you to sit back". It is an intellectual form of activism, which would be a significant legacy of the FMF movement because it would realise Gerwel's (2013: 249) injunction to fellow university activists that "[...] handing out pamphlets in the township isn't necessarily your change-seeking responsibility. An intellectual can change the world or contribute to the changing of the world through intellectual activity".

Erasmus wrote the following to her WFs:

\section{A cross-generational encounter}

Thank you for learning with me and for deepening the ways in which I learn with students. The most powerful element of working with you as Writing Fellows is the dialogic learning across generations through practicing writing as thinking.

In the 1980s I was one of few Black students admitted to the then 'for whites only' University of Cape Town as part of its affirmative action 'quota' during the apartheid era. Coming from a lower-middle-class family I struggled with the culture of the institution as much as with academic reading and writing. I taught myself to read by spending hours with texts. At first, I taught myself to write by imitating some authors. I eventually found my writing voice a few years after completing my formal university studies. The absence of Black thought in the humanities curricula of my student life means that I continue to re-educate myself. This place from which I entered life in the academy enables me to understand some of your struggles without simplistically equating the challenges I faced then with those you face today. I am encouraged by your explorations with writing as thinking as one way to engage the challenges of the academy critically, creatively, politically and

\footnotetext{
${ }^{11}$ In 2018, all WI lecturers and WFs were asked to write reflective evaluations of their work. Unfortunately, in this first year of the formalised grant-funded programme, we did not stipulate that all of the WI lecturers must collect standardised and systematic evaluation from the 5000-plus students enrolled in WI courses. This requirement will be incorporated into the second year's cycle and progress report.

12 See Erasmus (2017).
} 
thoughtfully. I am honoured to witness your finding voice and enabling your peers to find theirs. In terms of the university's hierarchy our cross-generational encounter has a reasonably long reach. It extends from me as the teacher, to you as senior post-graduates and Writing Fellows, to the junior post-graduates whose writing you facilitate, all the way down to the undergraduate students who are tutored by the junior post-graduates, and up along this learning route back to me. This learning-in-full-circle challenges the idea of a single story, a single way of being in the academy and the idea of a singular authority on knowledge.

\section{The course}

The sociology course during which we learned together focused on ways to recognise metropolitan methods of knowing on the one hand and on the other, on ways to dewesternise and decolonise thought and processes of coming to know. Its objective was to shift our sociological imaginations. Writing as a form of thinking and as a practice that promotes clear thinking and facilitates shifts in imagination helped us grapple with specific sets of questions. First: Whose theory is sociological theory? Where is the sociological imagination located? What is the dark side of this imagination? What are the implications of some answers to these questions? Second: What would dewesternising and decolonising social science and sociological theory imply? What can one do about the gaze of classical sociology? And third: Which other sociological imaginations are available to us as scholars? How might these be of value to us as scholars located in and thinking about South Africa and its place in the world?

As a team we helped students give life to the idea that theory is not waiting to be discovered on dusty library shelves in books written by white men who have long passed on. Instead, theory is about using, playing with and critically engaging with existing ideas in order to generate new ones. Thinking about ideas in this way enables us to claim our knowledge and experience here in the South with its colonial history. It encourages us to make ideas in which we can recognise ourselves and through which we can make strange what we have come to accept as truth. This approach presses us to free our imaginations from the discipline imposed by metropolitan theory and from the conformity expected from our social and learning milieu. It presses us to do what most of us are not taught at school namely, to think for ourselves. Regular writing helped students learn that thinking freely and for ourselves is neither a once off process nor an isolated activity. Your role as Writing Fellows helped them learn that independent thought grows through an iterative process that moves between being alone with words and being in community through mutual listening to each other's writing. Together we helped students learn that thinking for ourselves grows as we move between reading and writing. The sociologist Les Back reminds that ' $[t]$ he time spent reading and priming one's mind is always as long, if not longer, as the period spent hammering out the words on the keyboard' (2014: 57).

\section{Listening}

Let me share some of what I learned when listening to your sessions with students.

There is a gap between thought and its representation in words on the page, and between the spoken and written word. Reading our writing aloud helps bring ideas in our heads closer to the ideas on the page. When your peer grasps what you mean 
you are closer to getting your meaning across to the reader. Re-writing closes the gap between thought, the spoken word and the written word. It drives home that a good piece of writing cannot be done the night before it is due. To paraphrase the poet Adrienne Rich, we need to read and re-write as if our lives depend on it.

Your authoritative presence in the seminars gives students a sense of belonging and commitment to the course. They respect you as peers. When some say they 'want to be like you' I interpret this to mean that you inspire them to value learning and independent thought. This makes you an important advocate against learning-forcertification and against the commodification of thought.

Writing Intensive pedagogy cultivates a community of active epistemic agents. When we build community through writing as thinking and through the attentive conversation it requires, we stretch conventional notions of 'the classroom' beyond four walls, a black board and a teacher who wields power. The everyday lives of our students, their journeys to and from campus - literal and figurative journeys become classrooms, too. We do not need to extricate ourselves from our contexts in order to free our imaginations. Distance helps. At the same time, intimate and critical engagement with our lived realities is key.

Words are not the only means with which to write. We write with music, dance, numbers, paintbrushes, and images. Whatever the means, writing is always difficult.

Warm greetings,

Zimitri ${ }^{13}$

Erasmus' letter suggests that the listening and engagement in the classroom continued after the class, not only for the students and the WFs, but also for her as she reflected on her listening to their listening. Her classroom appears to have been alive with listening, and reading as listening. And so the ideas took shape - greater definition, nuanced position, and relational perspective between and within all the participants in the room. This excitement of thinking together is suggested by the enthusiastic reports from her WFs.

\subsection{Letters 2 and 3: WI lecturer and WF write to their students}

A key learning window in Erasmus' letter above is the direct, non-authoritarian though challenging address of the professor, who speaks to her WFs as future peers and fellow travellers on the difficult, but self-evidently not impossible, path to transforming ways of learning in the university. Nomonde Ntsepo and Lerato Mlahleki write as WI lecturer and WF, respectively, who are also peers. Ntsepo worked in the Wits Writing Centre (WWC) as a consultant before working as a lecturer in the Department of English at Wits University. She has since been recruited by Rhodes University. Mlahleki currently works in the WWC as a consultant, and is in the final stages of her research for a Master's degree in Sociology. Their classroom appears to be characterised by lateral power: through their own conversations about what and how to teach, and the prompting and listening to the ideas from and conversations of their students.

\footnotetext{
${ }^{13}$ For more information on Erasmus's course, please contact the Department of Anthropology at the University of the Witwatersrand where she currently works as an Associate Professor.
} 
Ntsepo writes from a discipline which has a long history of being tied to cultural imperialism ${ }^{14}$. She searches for ways to give her students access and engagement, and so change the use of the learning of literature from erasure towards presence. The technique of free writing offered a way of beginning not just to play with story but, as in Erasmus' lessons, to play with theory, in order to develop one's own theoretical position.

Ntsepo wrote the following to her students:

To fellow young academics,

When I think about writing this letter to you, what I most want to say is that a writing intensive approach offers a deeply thoughtful and engaged way of teaching, and it is this aspect that can be particularly rich for a new teacher and academic. For my writing-intensive course, I had the opportunity to design a third-year elective on Postcolonial Literature in English Studies. I chose to focus on two novels which are concerned with postcolonial travel and migration, and which provide an opportunity to discuss the postcolonial feminist debates surrounding these terms. I worked with a writing fellow, Lerato Mlahleki, both to design and teach the course, and this was extremely valuable, as we were able to teach collaboratively, and to consider questions of pedagogy together.

I know from conversations with many new young academics, both friends and colleagues, that many of us are thinking deeply and critically not only about what we teach (how to design a curriculum that is decolonial/feminist/antiracist/queer) but also about how we teach. In this letter, I focus on three of the questions that have emerged most frequently in my conversations with Lerato over the duration of the course: How do we present nuanced and complex material to students in ways that render that material accessible and relevant? How do we create engaged and participatory learning environments, in which students have opportunities both to learn and to create new knowledge? And finally, how do we create spaces for the knowledge that our students bring into the lecture hall, and place that knowledge into existing academic dialogues? These questions are clearly interlinked, and a writingintensive approach allowed us to begin to respond to each of them. We used many writing-intensive exercises, but for the purposes of this letter I have the space to think briefly about free writing.

In the course, students were expected to engage with postcolonial theory. One of the ways through which we found we could best facilitate this engagement was through free writing and guided free-writing exercises. Students had a chance to respond to, and then share their responses to the literary theory they read. The unguided free writing allowed students to think through their emotive responses to the theory they encountered, to pose the questions it raised for them, and to engage with it at a deeply critical level that allowed space for the affect it evoked. In this way, responding to readings through unassessed, low stakes writing facilitated student-led discussion on the readings, and helped to make the material both accessible and relevant. The guided free writing asked students to think through the ways in which the theory they

\footnotetext{
${ }^{14}$ See Viswanathan's (1989) seminal study.
} 
read linked to the specific literary texts we focused on, and to begin to construct some kind of argument in relation to this. This allowed students to begin to put their writing into conversation with other academic debates, and to approach writing as academic conversation. Feminist and postcolonial writing, which often challenges the notions of who can enter into academic discourse, and how, and from where, was an ideal place to practise this approach.

Free writing then, is just one writing-intensive exercise which demonstrated how a writing-intensive approach could be productive for young academics as they think about how to approach their teaching.

Yours sincerely, Nomonde ${ }^{15}$

Ntsepo's letter, like that of Erasmus', shows how the WI classroom promoted engagement and conversation.

Mlahleki, the WF for this course, is a sociologist, and so enters the disciplinary discussions as an outsider. Her gift to the students, as is evident in her letter below, is her skill at listening, her receptivity which allows the students to develop their own thoughts because they know that someone is really listening. I am sure this thinking with another was also characteristic of this particular partnership between WI lecturer and WF. Both Ntsepo's and Mlahleki's letters emphasise collaboration and shared thinking, and both expressed independently to me the hope that their future academic lives would include such opportunities for thinking together with colleagues.

Mlahleki wrote the following to her students:

To my fellow students and producers of knowledge,

I wish to thank you for an incredible semester of sharing yourselves, and feeling comfortable enough to share your knowledge, experiences and insights related to the subject matter with the entire class. It is not an easy thing to do, but the feedback you gave us made us realise the value that sharing had for you, as it had for us.

Both the anonymous and verbal feedback were of much benefit to us, and we plan on using this to assist us in continuing to develop a course that both fulfils the academic requirements (for the department), as well as your needs and your interests as you had expressed throughout the semester.

Most of you had expressed that you had struggled with the free-writing exercises and wished we had had enough time to practise this skill, as some of you expressed the usefulness this had for you. Due to time constraints we were unable to do more of these writing activities but perhaps in future we could gauge what the class finds most useful at an earlier stage.

\footnotetext{
${ }^{15}$ For more information on Ntsepo's course, please contact the Department of English Literature at Rhodes University where she currently works as a lecturer.
} 
In our last interaction, some of you expressed that you wished we had had more time to go through the essays and go into specifics such as 'what to do', 'what not to do' and the 'common errors' that students make in their essays. I absolutely agree! I also think that practice makes perfect (as perfect as can be - we are human after all!). As such, I ask that you continue to write in your spare time and explore different styles and evaluate which styles speak to you most and why this may be so. Writing is an amazing adventure and throughout this adventure, our experiences influence the decisions we make regarding our writing. It is perfectly okay to make mistakes - as a matter of fact, it is great when we make mistakes, because we learn from and build on them.

I really appreciate your openness and willingness to learn new things, even when these new things took you out of your comfort zone. I appreciate how you welcomed the idea and practice that writing is process, and that in each activity we undertook, we tried our best to relay this message. Thank you for trusting us and each other. Thank you for also being constructive and building each other, and us, gently and thoughtfully.

Yours truly,

\section{Lerato (your writing fellow)}

Ntsepo's and Mlahleki's letters, take different positions towards their students. Ntsepo guides her students towards entering the discipline, indicating through implication the ways that she has learned to participate in the discourse of literary studies. Mlahleki, on the other hand, models being a scholar without evaluating ways of engaging with, specifically, literary scholarship. Her role is to offer a friendly ear to their mistakes and revisions, to encourage them to experiment with style, and to help each other think further.

\subsection{Letter 4: A team of three WFs think themselves into their students' learning}

The final letter takes the form of a play or a transcript, showing how three young postgraduate WFs - Keanu Mabalane, Khensani Ngobeni, and Lew Is Ckool, coming respectively from the disciplines of Philosophy, Politics, and Publishing Studies - acculturated themselves to their large class of Theatre Performance students. Mabalane and Ngobeni have worked as WFs before in another discipline, while Lew is completely new to the programme. All have worked as WWC consultants, and Lew - an American - has worked in a writing centre in the United States. They speak together as equals and as a team. From a particular space and time, they think through, or act out, their task of designing their next lesson, and make connections between the thinking processes that the drama students already know, and the thinking that the students need to now perform in written argument. The task of the WFs is collective and pleasurable, and their process of constructing the lesson plan, as Lew observes, models the thinking processes and connections they are seeking to prompt in their students.

Mabalane, Ngobeni, and Lew wrote as follows: 
Section 1: What is the over-arching problem we identified?

[Setting: University of the Witwatersrand, Johannesburg at Wartenweiler Library Writing Centre Seminar Room. Wednesday morning at 11:00 am. Three Writing Fellows to the Applied Theatre Course discuss some ideas to draft a lesson plan to teach critical thinking to undergraduate students of the same course.]

Keanu: $\quad$ So, I am not sure I get what the main problem is here, Khensani?

Khensani: The students think they can't do academic writing. To them, it is for certain "educated" people and is far removed from the making and enjoying of theatre.

Lew: $\quad$ Ah, what if we incorporate the methods they used for that exercise they spoke about during their practicals?

Khensani: $\quad$ Yes, this will show them that they have the skills already and that they can adjust those skills to writing.

Keanu: Just to clarify, Lew, are you referring to their tableaux group presentations, where they had to choose a play, identify three themes, and then create a new shorter play?

Lew: $\quad$ Yes, that's the one.

Khensani: Okay now we have our problem. How do we link what they are doing in class to academic writing strategies?

Section 2: Our problem - How do we teach students to apply thinking skills from theatre to writing?

Lew: $\quad$ Right, I think we can do that by highlighting the method of enquiry they used to create their new plays, and then facilitating a process through which they transfer the same skills into their essay writing. This can help make their understanding of academia less rigid, which is one of our goals.

Khensani: We could discuss the methods they used, such as taking three themes from their plays. Then we go through the themes, how they were identified, and look into their process of selecting and emphasising excerpts. Afterwards, we replicate the process with the journal articles they have to read for their comparative essays.

Lew: [smiles and nods]

Keanu: I see how this could assert the idea that they have been practising this process already. How can we put that in the lesson, though?

Lew: $\quad$ They will look for key themes in the articles, and then find quotes that support these themes, and then discuss the quotes in their essays.

Keanu: [while playing with her pen]

Maybe we can ask them to get five themes at first, and then ask them to eliminate two. I think the aim here would be to help them attend to the thought process of interpreting a text post reading, and showing them just how active the thought process is, and well... should be if it's not. What do you think? 
Lew: $\quad$ Wow, I like that. This way, we are focusing their awareness on their process of reasoning as one of rational choice and judgement making!

Khensani: [emphasises points with hands]

And the point of that selecting task is to emphasise reason as the primary means of selecting themes. Hopefully, they will use the same tools to make their judgements and conclusions in writing the comparative essay too! This just makes sense!

Lew: $\quad$ Yep, link after link. There's almost a link everywhere but without study of their relations the links stay unnoticed. I like how with this task we are ultimately facilitating that process of thought although we call it "academic writing".

Khensani: I think this is really just a class for the making, not just of a critical scholar of Theatre Performance, but of a citizen scholar in general. To put it plainly, academia addresses topics about which all of us have opinions. I think it's made academic by the rigour of the logical reasoning or critical thinking. Like the distinguishing feature of academic thought is making connections between things. A sort of thinking about things not just thinking within them!

Section 3: Resolution and the makings of citizen scholar.

Lew: Well, don't you think that the very term is a bit exclusive after all? Keanu: Meaning?

Lew: I think that maybe a term like "critical thinking" might be more inclusive. It suggests nothing about who ought to be doing this, but it would seem applicable to anyone who just can think.

Keanu: In fact, speaking to Lew's idea about an inclusive term, the labelling does create a disjoint. If you think of academia as a stage, as this elevated part of society, then it makes sense why it's understood as something to be observed and not engaged with. But a performance is not just a stage: it's the people behind the scenes, it's the audience and its placement, etc.

Khensani: WHAT! I think I get it: the citizen scholar and the Theatre Performance student are not separate from what is actually happening in the world and thus they should engage the world.

Lew: Yeah...consider what's in the play, around it, the responses to it, as well as the socio-political moment it is happening in.

Khensani: $\quad$ You begin to make a link between all those things. So when you are in it you just laugh in response to some implied ironic notion. But as a critical thinker you start questioning "Why is this funny to me?".

Keanu: $\quad$ This applies to the playwright too! She would ask herself, "How do I wish for this to be read or understood generally?" and "Why am I making this joke? And what are the effects of presenting this idea or portrayal of this sort to the rest of the world?" 
Lew: Don't you guys love how we have gone through the same process from picking themes, as Khensani introduced, to using that last stage-space analogy to explain and describe critical thinking?

[Everyone laughs]

Khensani: $\quad$ Okay, now let's do the lesson plan...

The above play or transcript ends with laughter and confidence, which the lecturers report was infectious to the drama students. The lecturers were also happy about the way this course unfolded through regular analogies between disciplines, practices, and academic writing. This team of WFs was invited into the drama lessons, and improvised with the students as they then invited the students into learning together how to write. It appears a happy integration, process of mutual learning, and a confirmation - for this trio of friends at least - that effective engagement with ideas in the university context can lead to wider relevance and participation. Through this work, these WFs are creatively building themselves as future scholars working towards a university which is relevant and connected to our developing country. We need to build more of such experiences of creative collective learning, to counterbalance less happy places of learning which marginalise students rather than empower them.

\section{Conclusion: "Change emerges from what already exists"16}

South Africa has many poisonous residues from the past. A patronising, deficit model of learning is one such residue high on this list. On 7 June 1954, Dr Hendrik Verwoerd, in his capacity of Minister of Native Affairs, delivered a speech on the Bantu Education Act of 1953. This speech reveals sentiments which, if the term "Bantu" is removed, sound benign and familiar, and even, within a superficial reading, politically correct.

A Bantu pupil must obtain knowledge, skills and attitudes in the school which will be useful and advantageous to him [or her] at the same time beneficial to his [or her] community. The subject matter must be presented to him [or her] in such a way that he [or she] can understand and master it easily, making it his [or her] own, to the benefit of his [or her] community [...] The Bantu must be guided to serve his or her community in all respects.

[In Rose and Turner (1975: 262-265)]

This "respect" for cultural difference, and unchallenging lessons ${ }^{17}$ were part of the path to segregation and labour banks.

The WWP explicitly seeks to go in the opposite direction, to activate students and staff so they do not separate or learn to serve but rather acquire the tools to think for themselves, and together are able to choose how to write and act effectively, and if need be and opportunity presents, challenge the status quo.

\footnotetext{
${ }^{16}$ Christie (2008: 2).

${ }^{17}$ The assumptions of this speech suggest the removal of difficulty and challenge, and the limitations of aspiration. Such unquestioned assumptions by a teacher about her students are detrimental to any child's progress. However, the actual historical effects of the Bantu Education Act are disputed [see Giliomee (2012) and Hyslop (1993)].
} 
The voices in these letters illustrate this attempt at activation: all are actively pushing to listen harder, and to think further for themselves and for their students. All begin from particular positions with particular intentions towards particular audiences, and are engaged in open-ended, flexible, and strategic investigation. Their roles can change - the professor not only professes but also listens. They look for ways to open doors - the young lecturer reads her material to find a way to engage for herself, and to open avenues of engagement for her students. They are open to contradiction the WF listens intensely to her students, allows their responses to guide her, and helps them to build on what they know and think they can know. And lastly, they are collectively creative - the three WFs think together, and build on their collective improvisations in order to create learning bridges for their students and themselves. All are attentive voices, finding their meaning and their teaching directions through listening to others.

The political imperative implicit in Said's concept of 'attentiveness' is similar to Arendt's (1977) description of judgement. Arendt builds on Kant's idea of an enlarged way of thinking - eine erweiterie Denkingsart - and contrasts logic, which needs only the individual to prove itself sound, with judgement, which needs others to prove its validity. Judgement transcends the individual. Indeed, judgement, Arendt writes:

cannot function in strict isolation or solitude; it needs the presence of others 'in whose place' it must think, whose perspectives it must take into consideration and without whom it never has the opportunity to operate at all.

(Arendt 1977: 24)

Judgement, therefore, is thinking within simultaneity, thinking and communicating with others who will think differently but with whom we try to come to an eventual agreement. Taking this into consideration, skilful judgement is what we work towards in our research and in our teaching. Judgement is made after careful consideration of alternatives, qualifications, and context, is contingent on time and community, and is a key practice of the citizen scholar. Therefore, we need to model the attempt to practise this type of judgement, this art of creative, responsive, and intellectually responsible thinking within simultaneity, at all levels of the programme. Because if we do not manifest what we teach as best we can, why should our students follow our example?

\section{References}

Arendt, H. 1977. The crisis in culture: Its social and political significance. In H. Arendt (ed.) Between past and future. New York: Penguin Books. pp. 1-32.

Back, L. 2014. Writing as a movement of imagination: Reading as companionship. In C. Smart, J. Hockey and A. James (eds.) Thought in the craft of knowledge: Experiences of living with data. New York: Palgrave Macmillan. pp. 56-73. https://doi.org/10.1057/9781137287342_4

Bean, J.C. 1996. Engaging ideas: The professor's guide to integrating writing, critical thinking, and active learning in the classroom. San Francisco: Jossey-Bass Publishers.

Brenner, E. and P. Nichols. 2013. Critical Engagement through Writing (CEW): Using writing to promote thinking in large classes. In D.J. Hornsby, R. Osman and J. de Matos-Ala (eds.) 
Large-class pedagogy: Interdisciplinary perspectives for quality higher education. Stellenbosch: SunMedia Press. pp. 97-112. https://doi.org/10.18820/9780992180690/07

Carter, S. 2009. The writing centre paradox: Talk about the legitimacy and the problem of institutional change. College Composition and Communication 61(1): 33-52.

Christie, P. 2008. Opening the doors of learning: Changing schools in South Africa. Sandton: Heinemann.

Colomb, G.G. and J.M. Williams. 1990. The University of Chicago. In T. Fulwiler and A. Young (eds.) Programs that work: Models and methods for writing across the curriculum. Chicago: University of Chicago. pp. 83-113.

Delpit, L. 1995. Other people's children: Cultural conflict in the classroom. New York: The New Press.

Erasmus, Z. 2017. Race otherwise: Forging a new humanism for South Africa. Johannesburg: Wits University Press. https://doi.org/10.18772/12017090589

Gerwel, J. 2013. Living out our differences: Reflections on Mandela, Marx and my country. In J. Higgins (ed.) Academic freedom in a democratic South Africa: Essays and interviews on higher education and the Humanities. Johannesburg: Wits University Press. pp. 227-253. https://doi.org/10.1177/0725513612470531

Giliomee, H. 2012. Bantu education: Destructive intervention or part reform? New Contree: A Journal of Historical and Human Sciences for Southern Africa 65: 67-86.

Higgins, J. (ed.) 2013. Academic freedom in a democratic South Africa: Essays and interviews on higher education and the Humanities. Johannesburg: Wits University Press.

Hyslop, J. 1993. A destruction coming in: Bantu education or response to social crisis. In P. Bonner, P. Delius and D. Posel (eds.) Apartheid's genesis 1935-1962. Johannesburg: Ravan Press. pp. 393-410.

Nichols, P. 2014. Heeding the 'corpse in the cargo': The writing centre and the need to listen. South African Journal of Higher Education 28(3): 894-906. https://doi.org/10.20853/28-3-377

Nichols, P. 2016. Open-ended dialogue and the citizen scholar: A case study of the writing component of a university-led enrichment programme for school learners. In J. Arvanitakis and D.J. Hornsby (eds.) Universities, the citizen scholar and the future of higher education. London: Palgrave Macmillan. pp. 102-118. https://doi.org/10.1057/9781137538697_

Nichols, P. 2017a. "Hopeful" directions for writing centres in South Africa: From safe spaces to transitional sites of articulating practice. SPiL Plus 53: 182-194. https://doi.org/10.5842/53-0-741

Nichols, P. 2017b. Writing democracy: From writing centres to writing fellows to writing intensive courses in a university-wide writing programme. In S. Clarence and L. Dison (eds.) 
Writing centres in higher education: Working in and across the disciplines. Stellenbosch: SunMedia Press. pp. 35-48.

Rich, A. 1993. What is found there: Notebooks on poetry and politics. New York: WW Norton.

Rose B. and R. Turner. 1975. Documents in South African education. Johannesburg: AD Donker.

Said, E. 2013. Criticism and democracy. In J. Higgins (ed.) Academic freedom in a democratic South Africa: Essays and interviews on higher education and the Humanities. Johannesburg: Wits University Press. pp. 209-225.

Viswanathan, G. 1989. Masks of conquest: Literary study and British rule in India. New York: Columbia University Press. https://doi.org/10.1086/ahr/97.1.272 